\title{
Effects of Diagonal Bracing on Thermal Insulation of Wood-frame Walls
}

\author{
Mingbin Liu, ${ }^{\mathrm{a}}$ Feng Lu, ${ }^{\mathrm{a}, *}$ Xuedong Zhang, ${ }^{\mathrm{a}}$ and Xiaolin Yang ${ }^{\mathrm{b}}$ \\ The influence of various diagonal-bracings arrangements on the heat \\ transfer coefficient of wooden walls was studied with the goal of improving \\ the thermal insulation performance of the walls. Through the reliability \\ verification of the theoretical value of the heat transfer coefficient, this study \\ found that a larger proportion of wood frame area resulted in larger \\ theoretical and test values for the heat transfer coefficient. The heat transfer \\ coefficient of the wall with expanded polystyrene foam sheet (EPS) was \\ $5.90 \%$ to $6.10 \%$ higher than that with extruded polystyrene foam sheet \\ (XPS), and the tested value was $4.75 \%$ to $8.60 \%$ higher. The maximum \\ value of the average heat transfer coefficient of 12 diagonal-braced walls \\ was $0.366 \mathrm{~W} \cdot \mathrm{m}^{-2} \cdot \mathrm{K}^{-1}$, which met the thermal level of the severe cold area. \\ The test value of the heat transfer coefficient was larger than the theoretically \\ calculated value, and the linear correlation was up to 0.978 .
}

Keywords: Wall; Diagonal-braced; Insulation; Heat transfer coefficient

Contact information: a: Department of Industrial Design, Anhui Polytechnic University Wuhu, Anhui, China; b: School of Architecture, Zhengzhou University Zhengzhou, Henan, China;

* Corresponding author: liumingbin2019@163.com

\section{INTRODUCTION}

Wood-frame walls are the primary structural assemblies used in low-rise wood construction for effective thermal insulation performance. In North America, several studies have evaluated the thermal insulation properties of wood-frame walls. In a comprehensive study on the design of light wood-frame buildings with respect to energy conservation and heat insulation, reasonable planning and structural design were used to improve the thermal performance of wood-frame buildings, reveal the experimental parameters for materials, and derive a theoretical formula for calculating heat loss through design, construction, and experimental tests (Sherwood and Hans 1979). In 2008, the Engineered Wood Association (APA) conducted research on insulation of light wood frame walls. They expounded the effective measures to improve the heat insulation and energy conservation of wood-frame buildings from five aspects, including the materials of the wall, the air tightness of the wall, heat insulation, the sound insulation of doors and windows, and the installation of heating equipment. Smegal and Straube (2010) carried out a systematic study on a double-row stud and high-heat wall with external thermal insulation from the perspective of climate change in cold regions. To ensure a high level of heat insulation performance of wood-frame buildings, they proposed a thermal insulation strategy between the building foundation, basement, and the wall, which would meet the thermal insulation requirements of the cold region through controlling the building's air tightness. A study from the Oak Ridge National Laboratory (ORNL, USA) established the Zero Energy Building Research Alliance (ZEBRA) (Miller et al. 2010). They studied four newly constructed wood-frame buildings with various thermal insulation structures using 
structural insulated panels (SIP), optimizing frame structure (OVF), dynamic maintenance structure (DE), and exterior insulation and finish system (EIFS). In addition the study found that the thermal resistance of the external wall using SIP and OVF structures exceeded 4.4 $\mathrm{m}^{2} \cdot \mathrm{K} \cdot \mathrm{W}^{-1}$, and the energy consumption was about half of the current American building standard (Nyers et al. 2015), which demonstrated excellent thermal insulation performance. Forestry Product Innovations had published a guide for designing energyefficient building enclosures for wood frame multi-unit residential buildings in marine to cold climate zones in North America (Finch et al. 2013). This guide provided technical guidance and specifications for enclosure's energy conservation, heat insulation, air tightness, and air quality of wood-frame buildings in cold areas, it also provided reference basis for the design and research of the energy conservation and thermal insulation of wood frame buildings. Kucerova et al. (2014) studied the heat transfer coefficient of wood frame walls that had been used for many years. Based on this test, the $U$ value of the heat transfer coefficient was $0.04 \mathrm{~W} \cdot \mathrm{m}^{-2} \cdot \mathrm{K}^{-1}$, which was slightly higher than the simulated value by the software, but it met the current technical standards for heat insulation of wood-frame buildings. Blazek et al. (2016) used the calibrated heat box method to test the thermal insulations of four passive wood-frame walls. Having used the measured surface temperature and energy consumption to calculate the wall's heat transfer coefficient, they found that the error between the tested value, the standard value, and the empirical value was about $13 \%$. They compared the energy consumptions of the four walls and found that the energy consumption of the optimized fourth wall structure was approximately $39 \%$ lower than that of the non-optimized wall structure. Liu et al. (2018) studied the factors affecting the heat transfer coefficient of wood frame wall as well as the method of improving thermal insulation property of the wall. Twelve walls with various structures were tested by the hot box-heat flow meter test method. It was found that the moisture content of spruce-pine-fir (SPF), insulation materials, spacing, and thickness of studs had an influence on the heat transfer coefficient of walls. The effective heat transfer coefficient values of three walls ranged from $0.325 \mathrm{~W} \cdot \mathrm{m}^{-2} \cdot \mathrm{K}^{-1}$ to $0.398 \mathrm{~W} \cdot \mathrm{m}^{-2} \cdot \mathrm{K}^{-1}$, which met the thermal level $I_{t}$ of the severe cold area. With the wide application of wood-frame construction in different climate areas and the surge of new materials, thermal insulation and steady-state heat transfer properties of wood-frame walls were attracted great importance (Zarr et al. 1995; Dalgliesh et al. 2005).

This study evaluated the effect of the thermal insulation performance of wooden walls due to diagonal-brace and material proportion. The results offer scientific guidance for future design of wood-frame walls, especially with respect to anti-seismic and thermal insulation characteristics.

\section{EXPERIMENTAL}

\section{Wall Materials and Frame Structure Design}

Dimension lumber of spruce-pine-fir (SPF) was employed as the studs of wood frame walls, whose section size was $38 \times 89 \mathrm{~mm}$. Larch oriented strand board (OSB) and thistle board finish (TB) of $12 \mathrm{~mm}$ size were used as sheathings. Glass wool (GW) was chosen as insulation material; $30 \mathrm{~mm}$ expanded polystyrene foam sheet (EPS) or extruded polystyrene foam sheet (XPS) was applied as external insulation material. Felt ( $3 \mathrm{~mm})$ was applied between wood frame and TB as insulation material. Wood-plastic board was applied as a waterproof layer. Figures 1 and 2 illustrate the wall frame designs and their structures, which all refer to the Canadian wood frame house construction (Burrows 2005), 
and Chinese standard GB 50005 (2005).
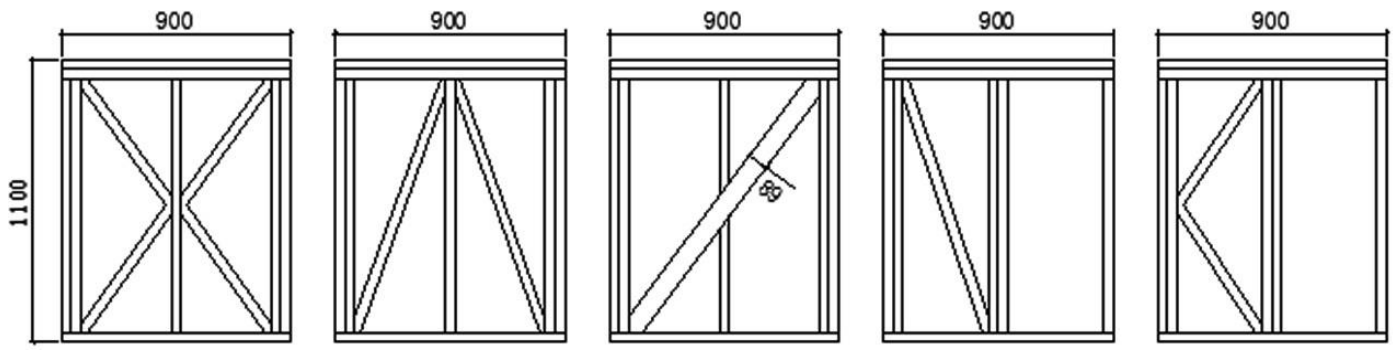

Fig. 1. The wall frame designs (the units shown are in millimetres)

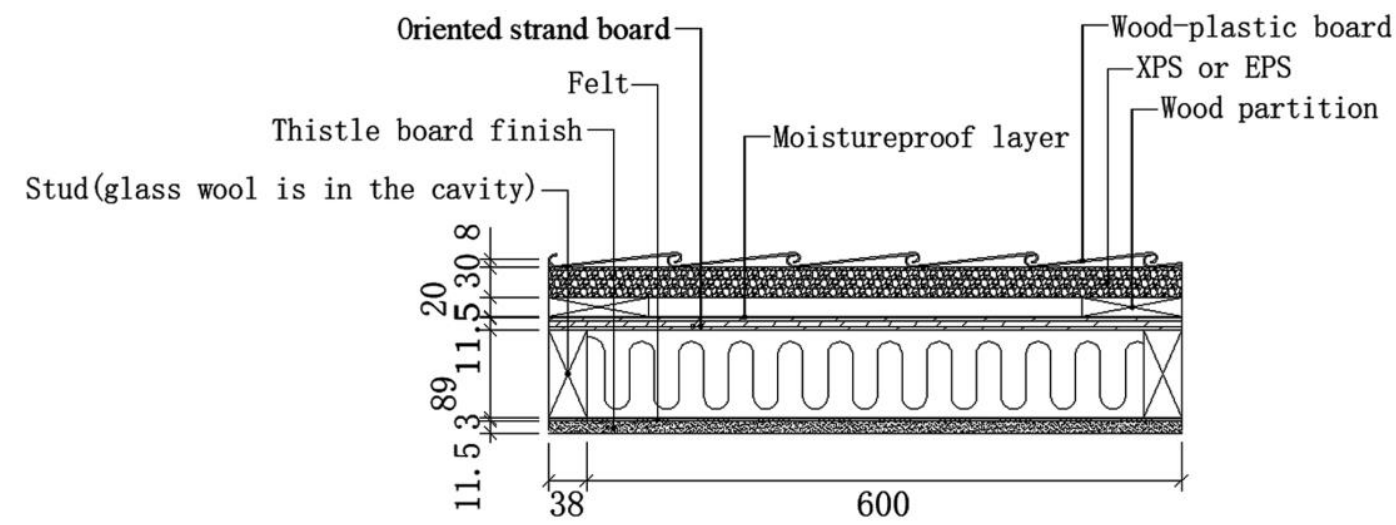

Fig. 2. The wall frame structure (the numbers at the left side of the figure are the thickness of each layer of material and the units shown are in millimetres)

\section{Wall Structures}

The structures and numbers of walls are shown in Table 1. The proposed structural systems met all the requirements of technical standards in terms of stability, sound insulation, and technical properties of the shells of buildings, fire resistance, and antiearthquake of living space.

Table 1. The Structures of Walls

\begin{tabular}{|c|c|c|c|}
\hline Samples & Type of Diagonal-braced & External Insulation Material & Wall Configurations \\
\hline$W_{E}$ & No & EPS & Standard wall \\
\hline$W_{X}$ & No & XPS & Standard wall \\
\hline$W_{S E}$ & Tenon inclined braced & EPS & Diagonal-braced \\
\hline$W_{S X}$ & Tenon inclined braced & XPS & Diagonal-braced \\
\hline$W_{X E}$ & X-shaped braced & EPS & Diagonal-braced \\
\hline$W_{X X}$ & X-shaped braced & XPS & Diagonal-braced \\
\hline$W_{\mathrm{RE}}$ & Herringbone braced & EPS & Diagonal-braced \\
\hline$W_{\mathrm{RX}}$ & Herringbone braced & XPS & Diagonal-braced \\
\hline$W_{\mathrm{DE}}$ & Monoclinic braced & EPS & Diagonal-braced \\
\hline$W_{\mathrm{DX}}$ & Monoclinic braced & XPS & Diagonal-braced \\
\hline$W_{\mathrm{KE}}$ & K-shaped braced & EPS & Diagonal-braced \\
\hline$W_{\mathrm{KX}}$ & K-shaped braced & XPS & Diagonal-braced \\
\hline
\end{tabular}

\section{Methods}

The thermal insulation performance of wall was tested by guarded hot box 
according to the GB/T 13475 (2008) standard. The guarded hot box was made up of three parts: cold box, hot box, and specimen box, as shown in Fig. 3. The steady thermal transmission was controlled by temperatures of cold box and hot box for constant temperature difference of cold and hot wall surfaces. The temperature and heat flow data were tested and recorded.
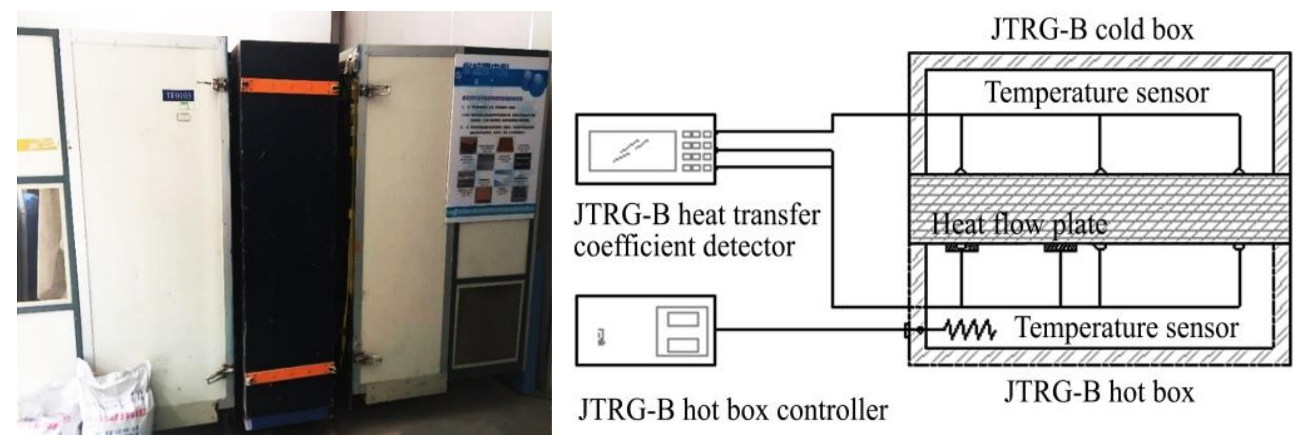

Fig. 3. The structure of guarded hot box

The heat flow passed through the wall from one side to the other side, and the temperature gradient decayed in the thickness direction. When the temperature on both sides of the wall reached dynamic equilibrium state, the steady temperature difference was kept on both sides of the wall due to the existence of thermal resistance. According to standard GB/T 13475 (2008), the surface temperature and air temperature on both sides of the wall were tested by temperature sensors, and the heat flow of the wall was tested by two rectangular heat flow sensors (one at the position of the stud and the other at the insulation). Air temperature measuring points were arranged in the suspended positions in the cold and hot box on both sides of the wall. The nine temperature sensors were arranged in the representative positions of thermal bridge and insulation cotton on both sides of the wall (TB and wood-plastic board). The heat flow plates were arranged at the middle stud and measuring point of insulation cotton, as shown in Fig. 4.
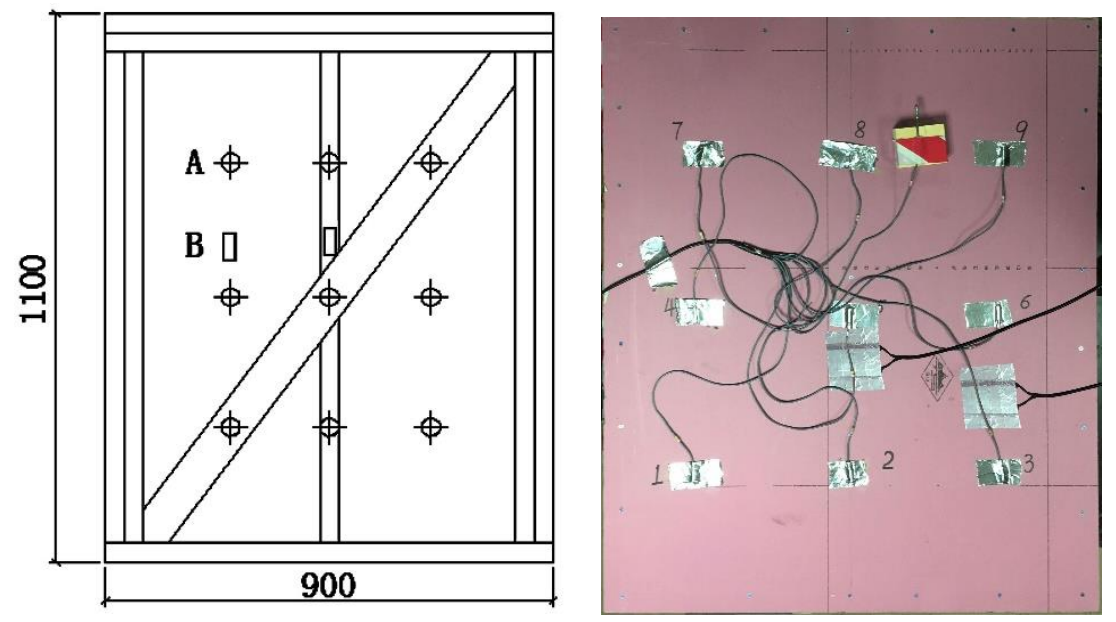

Fig. 4. The schematic diagram of measuring points. ( $A$ is thermocouple; $B$ is heat flow meter). 


\section{Calculation}

The heat transfer calculation of wood frame wall was based on the principle of onedimensional steady state thermal transmission. When the temperature of cold and hot box reached stable state after $96 \mathrm{~h}$, the heat transfer property of wall was calculated from air temperature, the two surface temperatures of the wall, and the power input to the guarded hot box. The total power input $Q_{\mathrm{p}}$ was corrected according to heat flow $Q_{2}$ of the wall and lateral circuitous heat loss $Q_{3}$. The heat flow $Q_{2}$ flowing through the wall and lateral circuitous heat loss $Q_{3}$ were calibrated by the specimen with thermal resistance, which are shown in Eq. 1,

$$
U=\frac{Q_{p}-Q_{2}-Q_{3}}{A\left(T_{h}-T_{c}\right)}
$$

where $U$ is heat transfer coefficient $\left(\mathrm{W} \cdot \mathrm{m}^{-2} \cdot \mathrm{K}^{-1}\right), Q_{P}$ is the total power $(\mathrm{W}), Q_{2}$ is the heat flow (W), $Q_{3}$ is lateral circuitous heat loss $(\mathrm{W}), A$ is the specimen area $\left(\mathrm{m}^{2}\right), T_{h}$ is air temperature of hot box $\left({ }^{\circ} \mathrm{C}\right)$, and $T_{c}$ is air temperature of cold box $\left({ }^{\circ} \mathrm{C}\right)$.

$$
U=K_{1} \cdot S_{1}+K_{\mathrm{S}} \cdot S_{\mathrm{S}}
$$

In Eq. 2, $U$ is the total heat transfer coefficient of wall $\left(\mathrm{W} \cdot \mathrm{m}^{-2} \cdot \mathrm{K}^{-1}\right), K_{\mathrm{I}}$ is the heat transfer coefficient of insulation cotton position $\left(\mathrm{W} \cdot \mathrm{m}^{-2} \cdot \mathrm{K}^{-1}\right), S_{\mathrm{I}}$ is the area ratio of insulation cotton to wall, $K_{\mathrm{S}}$ is the heat transfer coefficient of wood frame and diagonal-braced $\left(\mathrm{W} \cdot \mathrm{m}^{-2} \cdot \mathrm{K}^{-}\right.$ ${ }^{1}$ ), and $S_{\mathrm{S}}$ is area ratio of wood frame and diagonal-braced to wall.

\section{RESULTS AND DISCUSSION}

In this section, the analysis based on the tested data of the heat transfer coefficient $\left(W_{\mathrm{SE}}\right)$ of the wall was calculated according to the indoor and outdoor environmental air temperature, the wall's inner surface temperature of studs and insulation cotton position, the wall's outer surface temperature of studs and insulation cotton position, and the heat flow of studs and insulation cotton position. The temperature of each measuring point is shown in Table 2, and the temperature chart of measuring point is given in Fig. 5. Figure 6 shows that the heat flow of studs and insulation cotton. Figure 7 shows the heat transfer coefficient of insulation cotton and studs, and Fig. 8 shows the total heat transfer coefficient of wall. The data in Fig. 8 were obtained by applying Eq. 2 according to the heat transfer coefficient in Fig. 7 and the material ratio in Table 3. 


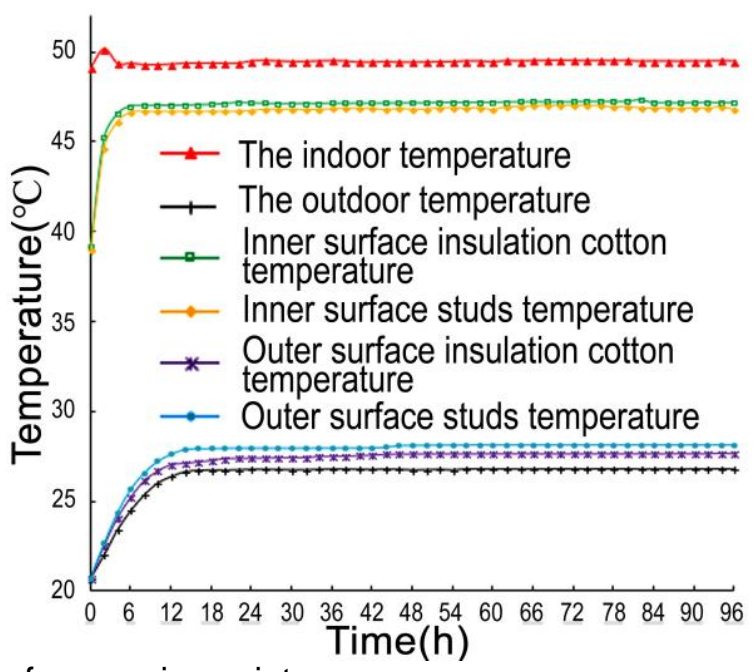

Fig. 5. The temperature of measuring point

Table 2. Temperature of Measuring Point

\begin{tabular}{|c|c|c|c|c|c|}
\hline $\begin{array}{c}\text { Indoor } T \\
\left({ }^{\circ} \mathrm{C}\right)\end{array}$ & $\begin{array}{c}\text { Outdoor } T \\
\left({ }^{\circ} \mathrm{C}\right)\end{array}$ & $\begin{array}{c}\text { Inner } \\
\text { Insulation } T \\
\left({ }^{\circ} \mathrm{C}\right)\end{array}$ & $\begin{array}{c}\text { Inner Stud } T \\
\left({ }^{\circ} \mathrm{C}\right)\end{array}$ & $\begin{array}{c}\text { External } \\
\text { Insulation } T \\
\left({ }^{\circ} \mathrm{C}\right)\end{array}$ & $\begin{array}{c}\text { External Stud } \\
T\left({ }^{\circ} \mathrm{C}\right)\end{array}$ \\
\hline $\begin{array}{c}49.14 \text { to } \\
50.17\end{array}$ & 20.7 to 27.12 & $\begin{array}{c}39.23 \text { to } \\
47.61\end{array}$ & $\begin{array}{c}39.07 \text { to } \\
47.33\end{array}$ & $\begin{array}{c}20.72 \text { to } \\
28.10\end{array}$ & $\begin{array}{c}20.70 \text { to } \\
28.62\end{array}$ \\
\hline
\end{tabular}

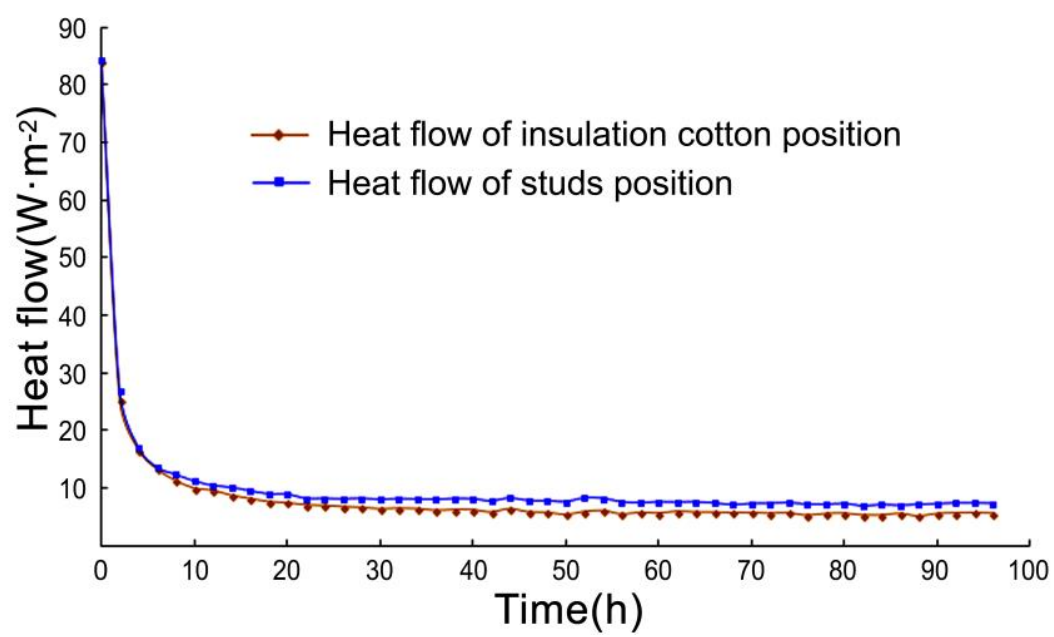

Fig. 6. Heat flow of insulation cotton and studs 


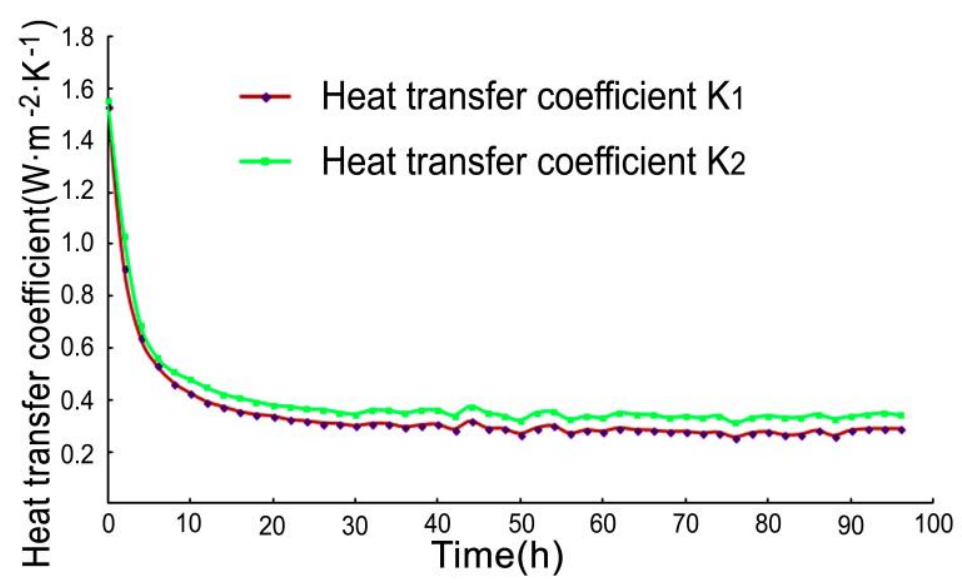

Fig. 7. The heat transfer coefficient of insulation cotton and studs

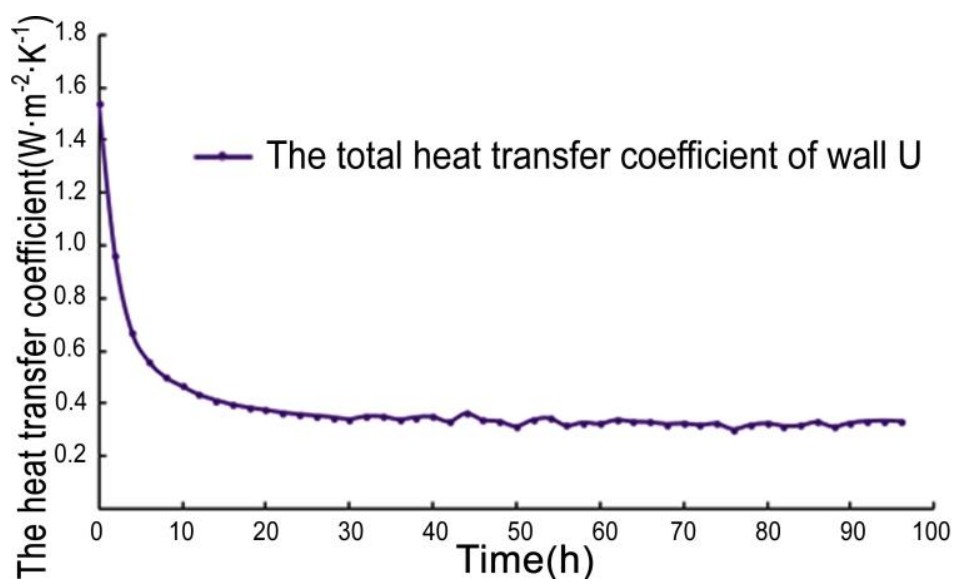

Fig. 8. The total heat transfer coefficient of wall

According to the calculation requirement of heat transfer coefficient in energysaving testing standard for residential buildings (JGJT132-2009), when a steady state has been reached, the temperature difference between the last calculation value of the building enclosure structure and that obtained before $24 \mathrm{~h}$ was no more than $5 \%$. The last heat transfer coefficient of this test was about $0.33 \mathrm{~W} \cdot \mathrm{m}^{-2} \cdot \mathrm{K}^{-1}$. The heat transfer coefficient before $24 \mathrm{~h}$ was $0.316 \mathrm{~W} \cdot \mathrm{m}^{-2} \cdot \mathrm{K}^{-1}$, and the temperature difference value was $4.24 \%$. Thermal transmission would reach a stable state in $12 \mathrm{~h}$ after the test, and the average value of heat transfer coefficient $K_{\mathrm{S}}$ at stud was $0.37 \mathrm{~W} \cdot \mathrm{m}^{-2} \cdot \mathrm{K}^{-1}$; The average heat transfer coefficient $K_{\mathrm{I}}$ of insulation cotton was $0.332 \mathrm{~W} \cdot \mathrm{m}^{-2} \cdot \mathrm{K}^{-1}$. The average heat transfer coefficient of stud position was $10.3 \%$ higher than that of insulation cotton position. Therefore, the thermal bridge effect of stud and diagonal-braced must be taken into account in the calculation of the total heat transfer coefficient. The effective thermal resistance or heat transfer coefficient should be used to express the thermal insulation performance of the wall, and the total heat transfer coefficient of the wall should be calculated according to the area weighting method. The ratio of insulation cotton area to whole wall area of $W_{\mathrm{S}}$ was $61.6 \%$, and the ratio of wood frame and diagonal-braced to the whole wall area was $38.4 \%$. Thus, the total heat transfer coefficient of the tested wall was $0.347 \mathrm{~W} \cdot \mathrm{m}^{-2} \cdot \mathrm{K}^{-1}$. 


\section{Comparison of the Theoretical and Measured Values}

According to the thickness and thermal conductivity of each layer material by the calculated using Eq. 2, the total heat transfer coefficient of wall was based on the heat transfer coefficient and area ratio of insulation cotton and stud. The heat transfer coefficient of insulation cotton and stud were $0.278 \mathrm{~W} \cdot \mathrm{m}^{-2} \cdot \mathrm{K}^{-1}$ and $0.373 \mathrm{~W} \cdot \mathrm{m}^{-2} \cdot \mathrm{K}^{-1}$, respectively. The total heat transfer coefficient of wall was $0.315 \mathrm{~W} \cdot \mathrm{m}^{-2} \cdot \mathrm{K}^{-1}$ based on area weighting method.

Table 3. Comparing the Theoretical Calculation with Measured Value of Heat Transfer Coefficient

\begin{tabular}{|c|c|c|c|c|c|}
\hline $\begin{array}{l}\text { Wall } \\
\text { Type }\end{array}$ & $\begin{array}{c}\text { Theoretical } \\
\text { Value }\left(\mathrm{W} \cdot \mathrm{m}^{-2} \cdot \mathrm{K}\right. \\
1)\end{array}$ & $\begin{array}{c}\text { Test Value }(\mathrm{W} \cdot \mathrm{m} \\
\left.{ }^{2} \cdot \mathrm{K}^{-1}\right)\end{array}$ & $\begin{array}{l}\text { Area Ratio } \\
\text { of Stud } \\
(\%)\end{array}$ & $\begin{array}{l}\text { Area Ratio of } \\
\text { Insulation } \\
(\%)\end{array}$ & $\begin{array}{l}\text { Relative } \\
\text { Error (\%) }\end{array}$ \\
\hline $\mathrm{W}_{\mathrm{E}}$ & 0.306 & 0.334 & 29.29 & 70.71 & 8.38 \\
\hline$W_{x}$ & 0.288 & 0.314 & 29.29 & 70.71 & 8.28 \\
\hline$W_{S E}$ & 0.315 & 0.347 & 38.44 & 61.56 & 9.22 \\
\hline $\mathrm{W}_{\mathrm{sx}}$ & 0.297 & 0.322 & 38.44 & 61.56 & 7.76 \\
\hline WXE & 0.315 & 0.366 & 38.31 & 61.69 & 13.93 \\
\hline Wxx & 0.297 & 0.337 & 38.31 & 61.69 & 11.87 \\
\hline$W_{R E}$ & 0.314 & 0.364 & 37.10 & 62.90 & 13.74 \\
\hline$W_{\mathrm{RX}}$ & 0.296 & 0.335 & 37.10 & 62.90 & 11.64 \\
\hline$W_{D E}$ & 0.310 & 0.340 & 33.09 & 66.91 & 8.82 \\
\hline$W_{D x}$ & 0.292 & 0.325 & 33.09 & 66.91 & 10.15 \\
\hline$W_{K E}$ & 0.314 & 0.364 & 37.46 & 62.54 & 13.74 \\
\hline$W_{K x}$ & 0.296 & 0.336 & 37.46 & 62.54 & 11.9 \\
\hline
\end{tabular}

The theoretically calculated value of the total heat transfer coefficient of wall is slightly smaller than test measured value from Table 3 . The calculated values of the heat transfer coefficients of walls were all less than test measured values. This was attributed to the $20 \mathrm{~mm}$ air layer between the moisture-proof layer and EPS or XPS, or the $3 \mathrm{~mm}$ felt between wood frame and TB. The gap permeates the hot air of the hot box into the cold box and the air layer, resulting in a smaller temperature difference between the thermal bridge and insulation cotton on both sides of wall. This test was carried out indoors under open air-conditioning. The temperature in the cold box was affected by the indoor air temperature, which caused the temperature difference of both sides of wall between the hot bridge and insulation cotton to be smaller and made the test measured value of heat transfer coefficient larger.

The error between the theoretical and the tested value of the heat transfer coefficient ranged from $7.95 \%$ to $15.6 \%$. The correlation coefficient was 0.978 , showing a high consistency. Therefore, the heat transfer coefficient of wall can be calculated by the thickness and thermal conductivity of each layer of wood frame wall even under the condition that the test equipment is not highly accurate, and therefore it can provide guidance for wall design.

A larger area ratio of stud and diagonal-braced wall resulted in a larger value of the theoretical calculated heat transfer coefficient and the heat transfer coefficient test value besides the tenon inclined braced wall $\left(W_{\mathrm{SE}}, W_{\mathrm{SX}}\right)$ values, because the thermal conductivity of stud and diagonal-braced (SPF) was nearly 2 times of that of cotton insulation. A larger thermal conductivity resulted in lower thermal resistance and a larger heat transfer coefficient. 


\section{Influence of Diagonal-brace on Heat Transfer Coefficient}

Comparing the diagonal-braced reinforced wall with the standard wood frame wall, the heat transfer coefficient of the diagonal-braced reinforced wall increased by $13.0 \%$ to $31.2 \%$. However, the maximum tested value of average heat transfer coefficient of wood frame wall was $0.366 \mathrm{~W} \cdot \mathrm{m}^{-2} \cdot \mathrm{K}^{-1}$, which met the requirements of inspection standard for thermal performance of on-site civil building energy conservation project DGJ32/J 232006. Also, the heat transfer coefficient of external wall should be less than $0.4 \mathrm{~W} \cdot \mathrm{m}^{-2} \cdot \mathrm{K}^{-}$ ${ }^{1}$ in severe cold areas, which met the thermal level $I_{\mathrm{t}}$ of the severe cold area. Thus, the antiseismic reinforced wall could slightly reduce the insulation performance of the wall, and still met the requirements of the technical specification for thermal insulation performance of the external wall in severe cold areas.

Figure 9 shows that a larger ratio of diagonal-braced to wall area resulted in a greater theoretical value of wall heat transfer coefficient. The tested value of the heat transfer coefficient ( $\left.W_{\mathrm{SE}}, W_{\mathrm{SX}}\right)$ of the wall was larger than that of the tenon inclined braced wall. This was because the thermal conductivity $\left(0.072 \mathrm{~W} \cdot \mathrm{m}^{-1} \cdot \mathrm{K}^{-1}\right)$ of SPF was nearly twice that of $\mathrm{GW}\left(0.041 \mathrm{~W} \cdot \mathrm{m}^{-1} \cdot \mathrm{K}^{-1}\right)$. The larger thermal conductivity reduced the thermal resistance and increased the heat transfer coefficient. When the wall was in the heat transfer state, heat flow was easy through the heat bridge of wood frame with higher thermal conductivity. The reason of the tested value of heat transfer coefficient ( $\left.W_{\mathrm{SE}}, W_{\mathrm{SX}}\right)$ becoming smaller with the increase of the area ratio of diagonal-braced was that the plane of tenon inclined braced forms a vertical relationship with the plane of stud and only the thinnest surface $(38 \mathrm{~mm})$ was embedded in the tenon groove of stud. In the direction of wall thickness, $38 \mathrm{~mm}$ thick SPF and $54 \mathrm{~mm}$ thick GW were formed, and thermal conductivity in the thickness direction of tenon diagonal-braced was between SPF and GW, and there was no direct heat bridge effect between cold and hot surfaces. As a result, the total heat transfer coefficient of the wall became smaller, the thermal resistance increased, and the thermal insulation performance was better.

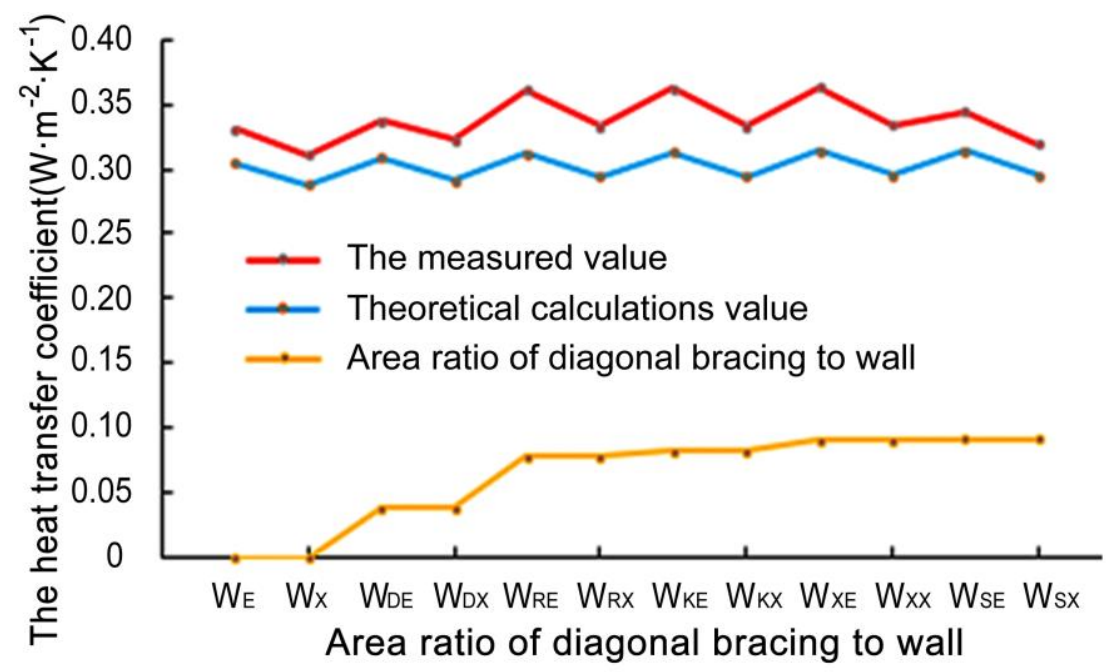

Fig. 9. Influence of diagonal bracing on the heat transfer coefficient of wall

\section{Influence of External Thermal Insulation on Heat Transfer Coefficient}

The heat transfer coefficient of the wood frame wall with EPS exhibited larger values than that using XPS, as shown in Fig. 10. The thermal conductivity of EPS was 
$0.031 \mathrm{~W} \cdot \mathrm{m}^{-1} \cdot \mathrm{K}^{-1}$, and XPS was $0.026 \mathrm{~W} \cdot \mathrm{m}^{-1} \cdot \mathrm{K}^{-1}$. Thermal resistance of EPS was smaller than that of XPS, which resulted in the heat transfer coefficient of the wall with external insulation material using EPS being $5.90 \%$ to $6.10 \%$ higher than the theoretical value of the wall using XPS, and $4.75 \%$ to $8.60 \%$ higher than the tested value of the latter.

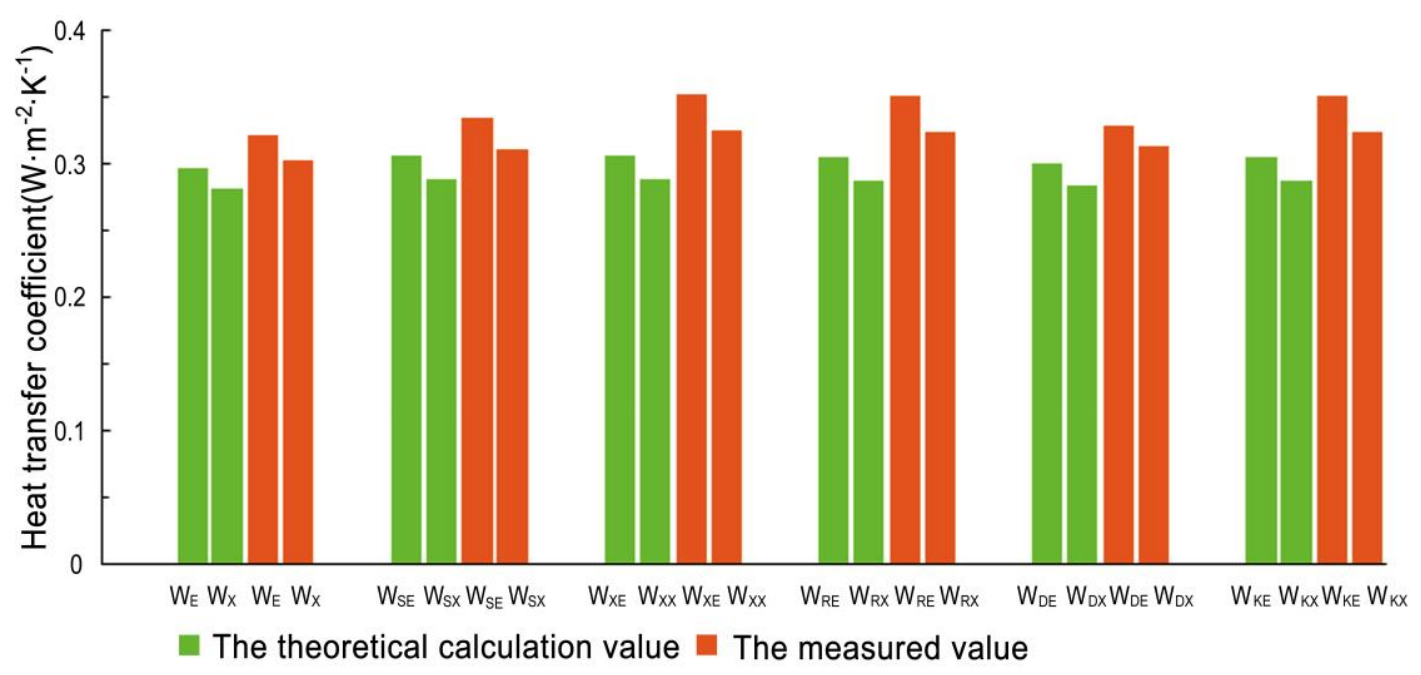

Fig. 10. Influence of external thermal insulation layer on heat transfer coefficient

\section{CONCLUSIONS}

1. The thermal insulation performance of wood-frame walls should be tested on the wood frame and insulation cotton positions, respectively. The effective heat transfer coefficient of the wall should be calculated according to area-weighting method.

2. The presence of a $20 \mathrm{~mm}$ air layer in the wall and the air-conditioning in the test room will cause little temperature difference between SPF thermal bridge and insulation cotton on both sides of the wall. The tested value of the heat transfer coefficient was larger than the theoretically calculated value, and the error ranged from $7.76 \%$ to $13.93 \%$. The correlation coefficient was 0.978 , showing a high consistency.

3. A larger proportion of wood frame area led to a larger theoretical value as well as a larger tested value of the heat transfer coefficient, except for the tenon inclined braced wall. This was because the thermal conductivity of SPF was nearly twice as high as that of GW. The better thermal conductivity of SPF led to the smaller thermal resistance and the larger heat transfer coefficient.

4. The heat transfer coefficient of diagonal-braced wall was $12.97 \%$ to $31.24 \%$ higher than standard walls. However, the maximum average heat transfer coefficient of walls was $0.366 \mathrm{~W} \cdot \mathrm{m}^{-2} \cdot \mathrm{K}^{-1}$, which met the insulation performance of the severe cold area (Level $\mathrm{I}_{\mathrm{t}}$ ).

5. The heat transfer coefficient of XPS was lower than that of EPS. This was because the thermal conductivity of EPS was $0.031 \mathrm{~W} \cdot \mathrm{m}^{-1} \cdot \mathrm{K}^{-1}$, while XPS was $0.026 \mathrm{~W} \cdot \mathrm{m}^{-1} \cdot \mathrm{K}^{-1}$. The heat transfer coefficient with EPS ranged from $5.9 \%$ to $6.1 \%$ higher than that with XPS, and the tested value was $4.7 \%$ to $8.6 \%$ higher than that with XPS. 


\section{ACKNOWLEDGMENTS}

The authors acknowledge the financial assistances from National Key Technology Research and Development Program of China (No. 2015BAL03B03) and Research Initiation Fund Project of Anhui Polytechnic University (No. 2019YQQ022) on this project.

\section{REFERENCES CITED}

Blazek, J., Mucka, M., and Trgala, K. (2016). "Cost and thermal- technical optimization of wooden construction in the passive standard," Wood Research 61(3), 663-672.

Burrows, J. (2005). Canadian Wood frame House Construction, $3^{\text {rd }}$ Ed., Canadian Mortgage and Housing Corporation (CMHC), Ottawa, Canada.

Dalgliesh, A., Cornick, S., Maref, W., and Mukhopadhyaya. (2005). "Hygrothermal performance of building envelopes: Uses for 2D and 1D simulation," Proceedings of $10^{\text {th }}$ Conference on Building Science and Technology 5(2), 32-41.

Finch, G., Ricketts, D., and Wang, J. (2013). Guide for Designing Energy - Efficient Building Enclosures for Wood - Frame Multi - Unit Residential Buildings in Marine to Cold Climate Zones in North America, British Columbia, Canada.

GB 50005-2005 (2006). "Code for design of timber structures: Design value quantities," China Standards Press, Beijing, China.

GB 50176 (2015). "Thermal design code for civil building: Calculation and measurement methods," China Standards Press, Beijing, China.

GB/T 13475-2008 (2008). "Thermal insulation - Determination of steady-state thermal transmission properties-Calibrated and guard hot box: Test and measurement methods," China Standards Press, Beijing, China.

GB/T 50361-2005 (2005). "Technical code for partitions with timber framework: Calculation methods," China Standards Press, Beijing, China.

Kucerova, L., Cernikova, M., and Hruba, B. (2014). "Thermal properties of wooden buildings in relation to computer software," Advanced Materials Research 899, 193196. DOI: 10.4028/www.scientific.net/AMR.899.193

Liu, M. B., Sun, Y. F., and Sun, C. (2018). "Study on thermal insulation and heat transfer properties of wood frame walls," Wood Research 63(2), 249-260.

Miller, W., Kośny, J., Shrestha, S., and Christian, J. (2010). "Advanced residential envelopes for two pair of energy-saver homes," ACEEE Summer Study on Energy Efficiency in Buildings, 1-244.

Nyers, J., Kajtar, L., Tomic, S., and Nyers, A. (2015). "Investment-savings method for energy-economic optimization of external wall thermal insulation thickness," Energy and Buildings 86, 268-274.

Sherwood, G. E., and Hans, G. E. (1979). Energy Efficiency in Light-frame Wood Construction (FPL-317), U.S. Department of Agriculture, Forest Service.

Smegal, J., and Straube, J. (2010). Building America Special Research Project: High-R Foundations Case Study Analysis, Building America Reports, Oxfordshire, UK.

The Engineered Wood Association (2008). Build Energy Efficient Walls, Madison, USA. 
Zarr, R. R., Burch, D. M., and Fanney, A. H. (1995). "Heat and moisture transfer in wood-based wall construction: Measured versus predicted," NIST Building Science Series 173, 1-2.

Article submitted: September 13, 2019; Peer review completed: November 9, 2019; Revised version received: November 12, 2109; Second revised version received:

November 19, 2019; Accepted: November 23, 2019; Published: December 2, 2019.

DOI: $10.15376 /$ biores. 15.1.517-528 